\title{
Language and happiness : Cultural epistemologies and ideological conflicts in Finnish online discourses on the causes of happiness
}

\section{Visakko, Tomi}

2020-03

Visakko, T \& Voutilainen, E 2020 , ' Language and happiness : Cultural epistemologies and ideological conflicts in Finnish online discourses on the causes of happiness ' , Language \& Communication, vol. 71 , pp. 39-54 . https://doi.org/10.1016/j.langcom.2019.12.003

http://hdl.handle.net/10138/338664

https://doi.org/10.1016/j.langcom.2019.12.003

cc_by_nc_nd

acceptedVersion

Downloaded from Helda, University of Helsinki institutional repository.

This is an electronic reprint of the original article.

This reprint may differ from the original in pagination and typographic detail.

Please cite the original version. 


\title{
Language and Happiness: Cultural Epistemologies and Ideological Conflicts in Finnish Online Discourses on the Causes of Happiness
}

\begin{abstract}
This article approaches "happiness" as a discursive construct. We examine different understandings of happiness as socially transmitted, linguistically formulated epistemological models by which humans reflexively evaluate and rationalize their experiences and identities. Our data consists of a set of Finnish online discourses that discuss the causes of happiness. We examine media platforms that mass-mediate popular discourses of happiness to individuals and allow individuals to voice their "indigenous" understandings. We analyze the linguistic, interactional, and interdiscursive characteristics of such views of happiness and show how they emerge and circulate in society disseminating mutually competing epistemologies of happiness. We also aim to show how the cross-cultural and culture-internal variation of these models becomes linked to ideological conflicts and politics of identity. On the one hand, our examples echo the kinds of individualistic, depoliticized views of happiness that have been seen as characteristic of modern media. On the other hand, they show that smaller-scale, local views of happiness tend to be more varied and attract explicit identity-political debates.
\end{abstract}

Keywords: Happiness, Discourse, Self-Help, Epistemology, Ideology, Identity

\section{Challenging reductionist views of happiness}

The research of happiness and well-being has experienced a considerable boom in recent decades, and much progress has been made in understanding these phenomena from psychological and neuroscientific perspectives. However, there has not been as much explicit discussion on the importance of language-use for happiness. ${ }^{1}$ Yet, in the past few decades, it has become widely accepted in many fields of study that the accumulation of everyday experiences is central to happiness and the capacity of people to improve their happiness by shaping their experiences through their own conscious efforts might be much more remarkable than was once thought. For instance, the school of positive psychology (see Seligman, 2002) maintains that happiness can be lastingly increased by such measures as bringing light to one's learned assumptions, ideals, and biases of interpretation. In other words, one of the goals in such approaches is to become aware of the socio-cultural and discursive habits one has adopted and to reflect on their effect on one's experiences.

In neurobiology, the term experience-dependent plasticity (e.g. Holtmaat and Svoboda, 2009) has been used to refer to the potential of the human brain to reorganize itself, sometimes to remarkable degrees, based on the accumulating experiences of the individual. Importantly, such brain-transforming experiences can be self-induced with specific cultural activity types,

\footnotetext{
${ }^{1}$ For example, in 10th August 2019, the World Database of Happiness listed 13954 publications in its bibliography, but the words "language", "discourse", and "interaction" occurred comparatively few times (WDH, 2019). Even in those few cases, language, discourse, or interaction seldomly played a key role in the study. Moreover, the studies often rely solely on self-reported data, such as questionnaires, rather than on an empirical analysis of actual language-use (cf. also Duncan, 2014, p. 80; Frawley, 2015, p. 63, 66).
} 
such as meditation (see Lutz et al., 2004; Chiao, 2009). In popular neuroscientific literature and self-help discourses, which have grown into an industry of their own, much has been made of these discoveries - and this "neuromania" has also been the target of extensive critique (see e.g. Tallis, 2011; Legrenzi \& Umilta, 2011; Frawley, 2015, p. 66-68). Numerous books and articles now formulate and disseminate advice on how to talk, think, and act in ways that supposedly change one's world of experience for the better. Their promise is that, by directing one's experiences systematically towards a specific direction, one can contribute to lasting changes over varying periods of time. Such models of self-directed experiencedependent plasticity (Schwartz, 2003; Hanson, 2013), then, directly implicate patterns of everyday social interaction and language-use. However, the central question becomes what "experience," ultimately, is and in what ways it can, or cannot, be "self-directed."

In this article, we adopt the stance that experience is the result of relational processes that cannot be reduced to the properties of brains or individuals alone (see e.g. Thompson and Varela, 2001). Experience becomes generated, evaluated, and re-organized in interactions between humans and their environments. The formation of experience is, in other words, distributed in interactional relations that involve a complex interplay of biophysical, social, and cultural dimensions. Even relatively private processes, such as perceptions, intentions, and emotions, are mediated by socio-historically accumulating cultural constructs. Moreover, the patterns through which humans interact with their environments are culturally learnt from and socially implemented with other people in organized social interactions. In other words, experience is inherently intersubjective by nature. (See e.g. Mead, 1934; Schutz, 1967; Kockelman, 2013. $)^{2}$ Moreover, experiences are subject to reflection, evaluation, and reorganization in subsequent events on different time scales. As will be seen in the following section, the representational and inferential capacity afforded by language is particularly important for such reflection. In fact, language has a role both 1) in the organization of those experiences that may become evaluated as happiness, and 2) in the evaluation of experiences as happiness or in the ascription of happiness to the self or others. Language, then, is both an experience-generating and an experience-evaluating instrument.

Importantly, "happiness" is both a scholarly term and a folk term. Many linguistic studies have focused on the semantic meaning of "happiness" and related terms in different languages of the world (e.g. Goddard and Ye, 2014; Levisen, 2014; Wierzbicka, 2004, 2011). Cross-linguistic and cross-cultural comparisons have shown that similar concepts can be found in many, if not all, languages but there is also significant variation in their contents (for problems related to such cross-cultural comparisons, see e.g. Wilce, 2009). In any case, it seems that relatively similar questions have been pondered for millennia in different scholarly and ethnotheoretical traditions, although their answers partially differ. At a very general level, "happiness" stands for a value that is both ultimate (i.e., not a means to some other end) and of the highest kind in its class (i.e., the most desirable one, above which no other ultimate

\footnotetext{
${ }^{2}$ Others may figure as co-present participants, such as collaborators or antagonists. They may figure as regimenting or recognizing institutional authorities at varying distances from the ongoing event. They may also figure merely as generalized others, that is, as social types whose attitudes we imagine, anticipate, and learn to take into account in our activities.
} 
goals rise). Happiness as a value involves a reflexive evaluation and classification of experiences to determine whether a given sample counts as a manifestation of happiness. At the same time, happiness itself is prototypically understood as something that can be felt or experienced within one's subjectivity. For instance, it might be associated with specific kinds of relatively lasting subjective states, such as feelings of pleasure or satisfaction. Happiness is an experience in itself, but it has its roots in other experiences.

Scholarly discussions of happiness have usually arrived at the conclusion that subjective states or individual experiences alone are insufficient or unsatisfactory as criteria of happiness (see also Griffin, 1998; Salmela, Pessi and Tissari, 2008). For Aristotle, for instance, only a state of satisfaction that is attained through virtuous activity in one's community counts as true eudaimonia (1098b30-31). Similarly, many Buddhist strains of thought emphasize the bodhisattva ideal, involving empathy towards others and actions undertaken for the benefit of others (see Ricard, 2006). Positive psychology, too, emphasizes the study of "positive institutions" and "positive traits", such as the culture-specific virtues to which an individual may lay claim (Seligman, 2002, p. xi). Even a purely hedonistic stance that equates happiness with individual feelings of pleasure can only foreground those feelings against a larger backdrop of human life. All models of happiness have to organize the different constituents of human life in preference hierarchies, some more explicitly, some more implicitly. We may conclude that, ultimately, models of happiness evaluate entire identities of experiencing individuals embedded in social relations with others. Our interest here is in the role of language-use in such processes. ${ }^{3}$

We argue in this article that any conception of "happiness" constitutes, first and foremost, a cultural epistemology, a socially transmitted, discursively formulated model in light of which

\footnotetext{
${ }^{3}$ Our understanding of happiness can be further illustrated by looking at the evolution of the Finnish adjective onnellinen, 'happy'. The pre-19 $9^{\text {th }}$ century meaning of the adjective was simply 'successful' or 'lucky'. Derived from the noun onni ('luck', 'fortune', 'chance', 'success') - like in many other languages (cf. Ahmed, 2007, p. 12 -13; Wierzbicka, 2011; Duncan, 2014, p. 82-84; Levisen, 2014, p. 180-181; Jugureanu et. al 2014) - the adjective onnellinen ('who has success/luck') was used in such sentences as "King Jeroboam was so onnellinen that he won back all that Hazael, the King of Syria, had conquered from Israel" (Cuningas Jerobeam - - oli nijn onnellinen että hän woitti caicki jällens mitä Hasael Syrian Cuningas oli saanut alans Israelin waldacunnasa) (1642 Bible translation). In other words, the adjective pertained to someone who had succeeded in their actions. (The Finnish equivalent for the verb "to succeed", onnistua, too, is derived from the noun onni.) Towards the late 1700 s, the modern meaning had become more prevalent. Two overlapping changes can be sketched. First, there appears to be a metonymic shift from UNDERGOER ('the one who has success') to EXPERIENCER ('the one who experiences the positive emotions caused by success'). Secondly, the ontological dimension of selfhood to which the 'success' pertains seems to have gradually risen from actions or social roles towards higher levels, such as entire lives, social identities, or souls. In its modern form, "happiness" models a particular type of 'ultimate success in selfhood'. However, it is important to note that before the word onnellisuus ("happiness") had acquired its modern meaning, there were other words pointing to more or less comparable epistemological constructs, such as the Christian-influenced autuus, '(spiritual) bliss'. In any case, the epistemology of happiness cannot be reduced to the semantics of the word "happiness" (cf. Levisen 2014: 177-178, 188). In fact, historically evolving and mutually competing epistemologies formulate both ultimate values (e.g., "bliss", "happiness") and highest-level dimensions of selfhood (e.g., "soul", "identity"). The flourishing and fading of specific constructs is catalyzed by a variety of intellectual currents and political forces (see also Bruckner 2010; Jugureanu et. al 2014).
} 
experiences and identities become reflexively analyzed and evaluated. ${ }^{4}$ That is, we approach happiness as a discursive construct, as the semantics of happiness-related vocabulary alone is insufficient for a precise understanding of how such terms are differentially used in actual processes of interpretation and evaluation. Moreover, such models often stand in an explicit dialogical relation to alternative models and the people committed to them. We illustrate how society- and language-internal variation in conceptions of happiness and its causes reflect broader ideological conflicts and politics of identity. Our approach aims to expand, from a linguistic perspective, previous critical discussions of the culture-bound aspects of happiness (see e.g. Ahmed, 2007; Jugureanu \& Hughes, 2010; Duncan, 2014; Frawley, 2015, p. 63-65).

Section 2 elaborates our theoretical approach. In section 3, we take an empirical look at different models of happiness and their dissemination through various digital channels and genres of social interaction, such as human interest and lifestyle portals, mass-mediated online feature articles, local blog writings, and grassroots commentary by readers. Phrased differently, we take a look at the global happiness industry from a Finnish standpoint with the aim of shedding light on how different models of happiness circulate and where they originate. We are particularly interested in the interface between online media and individuals. We examine media platforms that disseminate in a popularized form large-scale academic discourses of happiness to individuals amidst their everyday lives - reflecting the "discursive symbiosis between Anglo-International academia and the media" (Levisen, 2014, p. 175). However, at the same time, we look at platforms that, to some degree, allow individuals to voice their "indigenous" understandings of happiness publicly (e.g., as forum posts or blog comments) (cf. Frawley, 2015, p. 67; Levisen, 2015, p. 179). In section 4, we summarize our key findings and discuss their implications.

\section{Happiness as language-mediated evaluation of experience}

This section outlines our approach to language and happiness and discusses our central concepts and their mutual relations. By social interaction we refer to the organized patterns of interpersonal behavior in society on any scale, from intimate face-to-face conversations to mass-mediated communications, such as newspapers, TV programs, or blogs. On the one hand, social interaction involves mutually complementing social roles, joint activities, and coherent divisions of labor. On the other hand, it entails a dialectic of opposed identities, competing social roles, and conflicting activities. Both kinds of social relations are mediated by a variety of cultural norms, models, and values that circulate differentially among different

\footnotetext{
${ }^{4}$ Views of happiness are, therefore, active in both producing knowledge (whether there is happiness or not) and utilizing this knowledge (how or where happiness could be intentionally found or generated). In other words, the term "happiness" delineates a class of conceptual constructions, symbolic formations, or - more suggestively cultural fictions with very real consequences (see also Ahmed 2007). Even if one takes a strictly natural scientific stance in which the true indices of happiness are stress hormone or endorphin levels or brain wave activity patterns, such epistemological commitments are, still, mediated by sociohistorically specific, valuebound cultural assumptions. And such cultural assumptions stand in a dialectical contrast to, say, the Aristotelian model discussed above. In fact, in previous literature, the covert cultural normativity of scientismbound views of happiness has received a good deal of criticism (for a review, see Frawley, 2015, p. 64).
} 
socio-demographic segments of society. (See e.g. Agha, 2007; Kockelman, 2013; also Chilton, 2004, p. 3-4.) Culture, thus, is a more general term, as it refers to the kinds of socially transmitted and socio-historically evolving assumptions that underlie and organize particular interactions and interpretations. Language is a specific form of culture and a specific instrument of social interaction comprising both a system of lexico-grammatical forms and a repertoire of discursive practices, in which those forms become used as part of meaningful socio-cultural activities, such as genres of writing, sequences of conversation, or styles of self-presentation. ${ }^{5}$ (See e.g. Silverstein, 2003, 2004.) In our view, then, all attributions of "happiness" involve a set of socially transmitted cultural assumptions and become implemented in specific discursive patterns of social interaction.

Importantly, language can be used to model other modes of experience in highly explicit and structured terms. More specifically, language gives humans the capacity to represent experiences by using arguments to denote entities in some world of experience and predicates to characterize or classify the properties of or relations between those entities. While sentences organize experiences into structured representations, they also indexically link those representations to the speech event and the speaking subjects (e.g., deictically or modally). Each linguistic formulation construes its object differently by selectively articulating it from a specific perspective. For instance, the following three sentences from the internet all incorporate the noun "happiness" as an argument but represent it in entirely different ways.

(a) It was like a jolt of happiness hit me, and I don't know why.

(b) I achieved happiness by aligning my goals with my passion.

(c) Happiness is the skill to rejoice over what you have at your disposal.

Examples (a) and (b) both formulate a description of a particular past event or time frame, whereas example (c) is a generalized definition of what constitutes happiness. In example (a), the transitive predicate hit takes happiness as its subject (i.e., as the agent in charge of the hitting) and the pronoun $m e$, referring to the writer, as the object (i.e., as the patient undergoing the hitting). Consequently, happiness appears as a force that manifests itself as such units as "jolts" and arises in people without their active efforts or even without their awareness of the exact causes, as specified by the epistemic framing (It was like; I don't know why). Such formulations can easily be seen to correlate with the kinds of epistemological

\footnotetext{
${ }^{5}$ In semiotic terms, conventionalized patterns of language-use at different levels can be called symbolic. That is, they are socionormative, culture-specific patterns of meaningful conduct. Such symbolic practices are relatively "arbitrary" in the sense that they involve socio-historical contingency and could have, under different circumstances, turned out differently. (See e.g. Parmentier, 1994.) Individual members of cultural communities, whether national, ethnic, professional, interest-based, or other, learn such patterns of appropriate and effective language-use through imitation, sanctioning, and reflection in processes of socialization (see e.g. Schieffelin and Ochs, 1986). In other words, morpho-syntactic systems and discursive practices link perceivable and performable forms with specific denotational meanings and pragmatic functions. While such links usually evolve incrementally in long-term sociohistorical processes, they can also be consciously controlled and intentionally steered towards specific directions. That is, they become shaped, to varying degrees, by languageusers' ideas, beliefs, and values concerning, for instance, what kind of language-use counts as "polite," "beautiful," "sincere," - or "happy" (see e.g. Silverstein 1979).
} 
models that view happiness as an emotional state, as emotional states are prototypically not readily controlled by the experiencing subjects but arise in response to stimuli present in environments or ongoing interactional events. Also, the formulation implies that the state of happiness is more or less transient and can disappear in the same manner it appeared.

In contrast, example (b) implies that the state of happiness is relatively permanent and still ongoing at the moment of speaking. The predicate achieve takes the first-person pronoun as the subject and happiness as the object, reversing the transitive scheme of example (a). Moreover, the sentence incorporates another process as a means of achieving the state of happiness (by aligning my goals with my passion). Here, the state of happiness is the result of the reflexive actions of the writer. Happiness is represented as emanating from a self-induced coherence between affective-motivational values (passion) and long-term socio-intentional values (goals).

It is noteworthy that, in contrast to the first two examples, example (c) is a normative generalization of what happiness consists of according to the writer. Instead of describing the past experiences of the writing subject, it commits the writer to an epistemic and evaluative stance. Like example (b), it formulates happiness as a self-achievable state, a learnable skill, and as a specific kind of relationship between emotional attitudes and biographical facts. In contrast to example (a), happiness appears here precisely as the capacity to self-control one's emotional states. We can see from the examples that linguistic representations function as a major metacultural force (see Urban, 2001), as they can be used to make specific cultural assumptions explicit and to evaluate and to re-model them in analytical terms -- and in infinitely varying ways.

It is important to note that linguistic formulations are not merely an instrument of descriptive representation. Their use is linked to social statuses and identities in a number of ways. The public articulation of a specific formulation entails or projects a commitment in terms of which one's actions can be socially judged. That is, such commitments function as social statuses that are subject to explicit social regimentation. (See e.g. Brandom, 2000; Kockelman, 2006, 2013). One can be held accountable and made responsible for breaches of one's projected commitments. For instance, others may demand reasons or additional evidence. Alternatively, they may press for a correction of action or an adjustment of the commitment in question. Not being able to comply can have serious consequences for one's social identity, such as being classified as "unreliable" or "liar." Difference in formulation, then, is a difference in commitment and accountability. Any part of the internal logic of the commitment can be called into question based on contradicting beliefs or values. Languageafforded representational and inferential structure, then, enables a specific form of theoretical agency and discursive rationality. It makes analytical reasoning and social deliberation about the world possible. With language, one can formulate, justify, and proclaim ideological and epistemological stances (as in example c above). This capacity is particularly important for our discussion, since it is through such stances that value-laden conceptions of "happiness," and the social positionalities they entail, become explicitly negotiated. 
Another level of linguistic organization concerns the discursive practices according to which language-use becomes organized into coherent patterns in social interaction. Such organization constitutes an indexical layer of meaning in the sense that it relies on relations between co-present textual and contextual elements (see e.g. Silverstein 2003; Agha 2007). For example, face-to-face conversations involve specific practices of turn-taking and sequential organization that shape the interpersonal coordination of speech and other joint activities. Such practices include, for example, adjacency pairs, such as question-answer and invitation-acceptance/refusal. (See Sacks, Schegloff and Jefferson, 1974; Schegloff, 2007.) Face-to-face conversations also fall into a variety of activity types with specific norms and social structures, such as storytelling, elevator small talk, or doctor's appointments (e.g. Levinson, 1992 [1979]). In a similar vein, the composition of written texts is organized by a variety of generic models with particular kinds of prototypical macrostructures and functional steps (see e.g. Bhatia, 2004).

Furthermore, any pattern of language-use - along with co-occuring signs, such as gestures, postures, gaze, clothing, appurtenances, or other aspects of appearance - may become organized into recognizable registers or styles of conduct that stereotypically associate such features with specific social roles or personae (e.g., how doctors, left-wing politicians, or urban Muslim adolescents talk). Register models emerge in long-term socio-historical processes of enregisterment (Agha, 2007, 2015). Since particular models of happiness are often formulated and disseminated by particular types of people, such models may in themselves become enregistered, that is, recognizably associated with specific social types and their mutual relations (e.g., liberal vs. conservative; neuroscientific vs. religious). When forms of "happiness talk" become recognizably linked with forms of personhood, they can also be, for instance, parodically imitated by their opponents.

Discursive practices are underpinned by language ideologies, that is, a subset of cultural assumptions that specify the kinds of language-use that are considered appropriate and effective for particular kinds of purposes in particular kinds of contexts (see Silverstein, 1979, 2003; Gal, 1989; Irvine, 1989; Woolard and Schieffelin, 1994; Kroskity, 2004). As will be seen in the next section, models of happiness, too, sometimes include an explicit languageideological component. In fact, they may involve very precise and peculiar notions about the links between words and well-being. For instance, models of happiness may formulate ideological models of language-use in face-to-face conversations, specifying how talk in particular settings should be organized to produce happiness. In other words, in some of the examples, discursive practices are both the medium of dissemination and one of the targets of evaluation of a particular model of happiness. Such cases, then, open to empirical and critical scrutiny the reflexive relationship between a decontextualized ideological model of social interaction and the actually occurring patterns of social interaction documented by linguistic research.

Finally, we may sum up the discussion above and return to the question of happiness as cultural epistemology with more precise terminology. By cultural epistemology we refer to the socially transmitted assumptions in light of which some community of humans evaluates 
their identities and rationalizes their experiences (see e.g. Kockelman, 2010; Bateson, 1972). We propose that specific epistemologies of happiness may be analyzed in terms of epistemic formations (Kockelman, 2006, 2013). Epistemic formations are processes in which epistemologies become concretely manifested and operationalized. Such processes coordinate the relations between empirical observations, theoretical representations, and practical interventions. That is, they organize the ways in which people

1) observe their worlds of experience (e.g., their emotions, social statuses, or other biographical facts) in some setting,

2) rationalize those observations by formulating them into theoretical representations (e.g., a pattern of propositional formulations about happiness or its causes and consequences), and

3) act on what they observe based on their theories (e.g., in order to change or to reinforce their situation).

Different epistemic formations direct our perceptions and intentions in different ways. Epistemic formations, then, are not merely "ways of speaking" about phenomena but, rather, modes of observation and intervention. ${ }^{6}$

In the following sections, we examine three cases that illustrate how competing views of happiness and its causes become linguistically formulated and interactionally disseminated and how language-use itself becomes implicated in such epistemologies of happiness. Our data have been gathered from different digital channels and genres of social interaction in which the participants discuss the causes of happiness: human interest and lifestyle portals, mass-mediated online feature articles and local blog writings. In these cases, the discursive practices have become mediatized. That is, they have become linked to socio-economic divisions of labor in specific ways. (See e.g. Agha, 2011; Irvine, 1989.) By focusing on publicly mass-mediated texts that discuss the causes of happiness - instead of, for example, local texts that only describe happy situations or experiences - we gain better access to epistemic formations that are both influential and have been explicitly fleshed out.

3. Global and local epistemologies of happiness: A Finnish perspective on the world-wide happiness industry

\footnotetext{
${ }^{6}$ Although they involve propositional representations, there are always collateral assumptions and concrete embodied techniques involved that do not receive propositionally explicit formulations (see also the discussion of "ethnotheories" in e.g. Douglas, 1972; Tambiah, 1985; Silverstein, 2004). In other words, theoretical representations are merely one aspect of such formations. This is why their usage should be observed in actual situated contexts, as will be illustrated in section 3 . The study of happiness, for example, would benefit from the use of ethnographic methods instead of relying on questionnaires or interviews alone (see also Frawley, 2015, p. 63, 66; Ahmed, 2007, p. 9). Similarly, the linguistically formulated beliefs that people have about their own interactional conduct can be in contradiction with how they actually behave, as their self-awareness is limited in a number of ways (which seem to exhibit certain regularities, see Silverstein, 2001).
} 
In this section, we take a Finnish perspective on the global "happiness industry" (see also Ahmed, 2007, p. 7; Duncan 2014, p. 83-84) or the network of institutions and individuals that more or less systematically - and often for commercial or political purposes - produce, repackage, and disseminate discursive models of happiness. We ask how the products of the industry find their way into the public discursive sphere for consumers to internalize - or to ignore. We examine three cases of mass-mediated Finnish-language models of happiness, each linked to a specific kind of channel, social activity, and interactional configuration. The aim of each analysis is to show 1) the specific nature of the channel of interaction, 2) the social types of the participants, especially the ones who initiate the topic of happiness, 3) the parameters of the activity type as well as the interests and motivations behind it, and 4) details of the formulation and composition of specific epistemic formations.

Models of happiness become disseminated in a wide variety of contexts. The selected examples, therefore, include ones in which happiness is the focal topic $(3.1,3.2)$ and ones in which happiness becomes implicated more indirectly (3.3). Similarly, the lexical forms used to evoke the phenomenon of happiness vary. In the description of everyday events $(3.2,3.3)$, the adjective "happy" or the adverb "happily" often suffice to ascribe states of happiness to individuals, whereas the noun "happiness," delineating a more abstract entity, is needed for more analytical purposes, such as philosophical or instructional discussions (3.1).

An influential source for models of happiness is the wealth of self-help books, magazines, and websites that offer practical instruments for self-analysis and self-transformation. The first subsection (3.1) deals with examples of happiness talk on self-help websites that are either popular or visibly advertised to Finnish audiences. It turns out that structurally similar models sometimes differ greatly in terms of the underlying social and economic dynamics. In the second subsection (3.2), we look at internet forum and comment section discussions in which individuals share their experiences of happiness with others and reason about the causes of their happiness. In some sense, such discussions represent "spontaneous" or "authentic" ethnotheories of happiness, but as it turns out, their spontaneity is a relative notion. Finally, in the third subsection (3.3), we take a look at an intertextual chain that starts from an American lifestyle blog text giving instructions on how to achieve "happy" results in parents' interactions with their children. By way of international mass-media recontextualizations, it ultimately ends up giving rise to a Finnish blog response that formulates a strict counter-model in opposition to the original one. The final example, then, concretely crystallizes some of the global dynamics of the present-day happiness industry. Ultimately, we aim to show how language-mediated epistemologies of happiness become caught up in socio-political dialectics between different identity types in society.

\subsection{Online self-help discourses of happiness}

"Self-help" here refers to the kinds of publications in which the authors appear as experts giving practical advice on social and psychological questions. Although the classical self-help book format is still very much viable, the rise of commercial online magazines, blogs, and 
portals has introduced an easily accessible alternative. The first example is from a website named Askel terveyteen ("A step to[wards] health"), a commercial portal that aims to profit from selling advertisement space and re-use rights to their texts. ${ }^{7}$

The writing examined here is a representative example of a recurring type of article on such portals. It is titled 10 ohjetta onnelliseen elämään ("10 guidelines to happy life"). We may note at the outset that the text utilizes a rhetorical device popular in self-help and lifestyle journalism, the enumerated list, which divides the treatment of the subject into a set of distinct parallel subunits. The question of happiness is first evoked by the adjective "happy," which frames happiness as a characteristic or quality of events of life rather than as an isolable phenomenon in its own right. Semantically speaking, the phrase "happy life" is embedded in a directional construction that construes it metaphorically as a destination, or a kind of "desired hidden object" (Kövecses, 2008, p. 140), that can be reached by travelling a certain path, or an end that can be attained by using certain means (c.f. Lakoff, 1987). The means to achieve happiness are described as "guidelines" or "instructions," that is, as authoritative verbal constructs received from someone else. As will be seen in detail shortly, the instructions are formulated as directives addressed to the reader in the second person, as a co-present "you." In other words, the text formulates happiness as a future goal that can be obtained by following a fixed list of instrumental activities dictated by an authority (cf. 3.2). ${ }^{8}$

After two introductory paragraphs, the text continues with ten segments that deal with the ten instructions one by one. They are all organized under the second-level subheading Mistä onnellisuus syntyy? ("How happiness arises"). Here, we find the first occurrence of the noun "happiness." Each segment is then headed by a directive-form subheading addressed to the reader in the second person: "Spend more time outdoors," "Sweat," "Sleep more," "Meditate," "Get a new hobby," "Listen to positive music," "Write about your experiences and concerns," "Be grateful," "Be a good friend," "Spread happiness and joy around you." The heading hierarchy, thus, organizes the contents of the ten segments as causes leading to happiness as a joint consequence. The interpersonal and representational dimensions of the text overlap in particular ways, as the heading structure frames each segment from two complementing perspectives. Each segment both gives instructions to the reader on the conditions of (their) "happy life" and simultaneously argues for the general causes of "happiness" as understood within this particular model.

After each directive, one or two paragraphs of text elaborate and explain the purpose of the directive. ${ }^{9}$ Under each heading-level directive, the text alternates between third person $(3 \mathrm{SG})$

\footnotetext{
${ }^{7}$ https://askelterveyteen.com/10-ohjetta-onnelliseen-elamaan/

${ }^{8}$ There is, then, an obvious resemblance with such archetypal forms of legal and moral discourse as the Ten Commandments or other Old Testament decrees, such as dietary restrictions related to "purity" (see e.g. Douglas 1972). What the model does not clearly specify are the mutual relations between the listed objects: Should they be followed in order? Are they all necessary conditions of happiness or can one cherry-pick? In other words, many aspects of how, exactly, one should use the model as an existential map in one's life remain undetermined.

${ }^{9}$ Between the paragraphs photographs echo the contents of the text by conveying typical glossy self-help imagery, for instance, pictures of women posing dynamically with their arms extended in meadows, fields or on
} 
factual generalizations and more specific applications of those generalizations that are addressed to the reader in the second person $(2 \mathrm{SG}):^{10}$

\section{(1) Kirjoita kokemuksistasi ja huolenaiheista}

\section{"Write about your experiences and concerns"}

Jokaisen tielle osuu kommelluksia, stressaavia aikoja ja vastoinkäymisiä.

"Mishaps, stressful times and adversities occur on everyone's path." [3SG, general problem]

Hyvä tapa käsitellä näitä on kirjoittaa niistä.

"A good way to process them is to write about them." [3SG, general solution]

Voit pitää säännöllistä päiväkirjaa tai kirjoitella ajatuksiasi ylös satunnaisesti:

"You [= anyone, including the reader] can keep a regular journal or write up your thoughts

randomly: [2SG, generic specification to the solution]"

löydä oma tapasi käsitellä elämässäsi tapahtuvia asioita kirjoittaen.

"find your [= the reader] own way to deal with things that happen in your life, by writing. [2SG

directive, encouraging the reader to apply the solution]"

Kirjoittaminen voi auttaa selkiyttämään ajatuksia ja helpottamaan ahdistunutta oloa.

"Writing can help clear the thoughts and ease the anxiety. [3SG, general fact justifying the solution]"

Kokeile kirjoittaa ylös kaikki negatiiviset ajatukset ja huolenaiheet, rutista sivu

paperitolloksi ja heitä se roskiin.

"Try writing up all negative thoughts and concerns, crumple up the page into a ball and throw it to the bin. [2SG directive, applying the fact to the reader's case]"

Tämä symbolinen ele kertoo aivoillesi, että nämä negatiiviset asiat eivät kuulu ajatuksiisi

enää.

"This symbolic gesture tells your [= anyone's] brain that these negative things do not belong to your thoughts anymore. [2SG, generic explanation of the effect of the solution]"

Kirjoita miettimättä oikeinkirjoitusta tai tekstin sujuvuutta, anna kynän lentää ja pura

oloasi papereille.

"Write without thinking about orthography or the fluency of the text, let the pen fly and channel your feelings to the paper. [2SG directive, specific instructions concerning the solution]"

Through such patterns of formulation, the text projects distinct roles for the writer and the reader: an advisor with epistemic (i.e., knowledge-related) and deontic (i.e., norm- or statusrelated) verbal authority and an advisee who is supposed to enact the instructions. Similarly,

beaches; relaxed- or dreamy-looking persons with peaceful smiles on their faces; and people caught up in a joyful embrace. That is, many pictures portray people exhibiting perceivable, stereotypic signs of specific mental states while often immersed in some pleasant social activity or aesthetically pleasing natural environment. Both the verbally and photographically mediated imagery, then, function as models for the experience of happiness and the activities or environments it supposedly involves. The pictures, however, appear more embellished and seem to vary less from one publication to another (many of them probably being stock photographs from similar sources). In any case, the editorial processes behind the writing and the pictures differ, and the focus here is on the writing.

${ }^{10}$ Also, in each of the paragraphs, one or two sentences are emphasized visually in bold characters.

Functionally, these sentences are either factual generalizations or directives addressed to the reader, like "Positivity creates more positivity and draws similar people together" and "Think about what you could do better as friend". 
there is an alternation between claims to factual knowledge and instructions derived from those facts by the writer and addressed to the reader. Let us now take a more detailed look at the $2 \mathrm{SG}$ elements and the kinds of social relations they mediate.

\section{Addressing models of happiness to readers}

Directives are a large class of linguistic expressions that are used to guide, instruct, or command others (see e.g. Sorjonen, Raevaara, and Couper-Kuhlen, 2017). That is, they describe some state of affairs that the addressee is expected to enact, whether by their own volition or because of social compliance. It is noteworthy that in the example, and in self-help discourses more generally, it is common to use direct imperative sentences ("Spend more time outdoors," "Think what you could do better as a friend"). In a mass-mediated (one to many) and asymmetrical (expert writer to lay readership) context, the imperatives may be addressed without hedging or softening, or anything understood as signs of a "polite" register that one might expect in one-to-one encounters between individuals. To put it differently, such formulations presuppose an epistemology according to which the conditions of happiness may be mass-transmitted via such propositional descriptions of intentional activities. In addition to physical or cognitive acts, imperatives may also be targeted at emotional processes: "Be grateful of the good aspects of your life: family, health, workplace, home, food and hobbies." Such formulations, then, construe emotional processes, too, as something that the addressee supposedly has intentional agency over. ${ }^{11}$

Moreover, 2SG references are used in a variety of discursive structures that complement the imperatives. For instance, questions concerning the discussed activities can be addressed directly at the readers: "When was the last time that you thanked someone?" Such questions propel each reader to look for signs or symptoms of the phenomenon in their own life. In a similar vein, the writer can offer explanations of causalities or regularities that are claimed to apply to the generic reader's life: "When you spread positivity and well-being around you, you also get loads of it back."

There are, thus, at least three types of frames involved in the linguistic mediation of the relationship between the writer and the reader. We might call them directive frames, diagnostic frames, and explanatory frames. Directive frames, in particular, are used to suggest practical interventions that supposedly lead to happiness. Diagnostic frames, in turn, focus on empirical observations and aim to highlight signs of happiness (or the lack thereof) in the reader's own world of experience. Explanatory frames consist in explicitly theorizing the underlying links between specific interventions and observations. In such epistemic formations (see Section 2), each component receives a relatively full discursive treatment and is associated with specialized discursive patterns.

In the previous example, and in many others like it, the facts that back up the directives may be presented as being based on general experience ("Many feel that from exercise they get

\footnotetext{
${ }^{11}$ Yet, the concrete steps through which this (emotional) state should be achieved in practice and implemented in actual social interactions, is - as is typical of such instructions - not discussed in the text in any detail.
} 
power and energy to their days") or scientific knowledge ("The green color has been scientifically proven to produce feelings of happiness and positivity, and mental balance and serenity"). Sometimes no sources, evidence, or justifications are presented, and the content is presumed self-evidently true ("Hobbies bring forth self-confidence, open the world and bring new acquaintances and friends to your inner circle"). The inferential link between the explanatory claim and the $2 \mathrm{SG}$ directive is often explicitly marked in text. In the example, we find, in fact, a recurring formula that involves the particle siis ('so,' 'thus,' 'therefore') which presents the directive as the logical conclusion from the given fact:

(2) Hymyilyn on todettu vapauttavan hormoneja, jotka vaikuttavat mielialaan positiivisesti. Hymyile siis vastaantulijoille tai kaupan kassalle - pian huomaat, miten nostattava vaikutus sillä on! 'Smiling has been noted to free hormones that affect the mood positively. So smile at the people you meet or to the cashier at the grocery store - soon you will realize, how elevating effect it has!'

(3) Musiikki laskee stressiä ja pitää mielen positiivisena, älä siis aliarvioi musiikin tärkeyttä sillä sekin viitoittaa tietä onnelliseen elämään.

'Music lowers stress and keeps the mind positive, so don't underestimate the importance of music because it too shows the way to happy life.'

(4) Kun jaat positiivisuutta ja hyvää oloa ympärillesi, saat sitä myös roppakaupalla takaisin, ja olet jälleen matkalla onnelliseen elämään. Pyyhi siis myrtynyt ilme naamaltasi ja katso ihmisiä silmiin, , hymyile, kiitä, kehu ja kerro, miten tärkeitä läheisesi sinulle ovat.

'When you spread positivity and well-being around you, you will get spades of it back, too, and you are on your way to a happy life again. So wipe the sullen expression from your face and look people in the eye, smile, thank, compliment and tell your loved ones how important they are to you.'

There is, then, a specialized pattern (GENERAL FACT + siis +2 SG-IMPERATIVE) of presenting models of happiness to readers in such mass-mediated interactions. We may note that the pattern structures the pursuit of happiness into a series of individualized tasks derived from supposedly objective facts. Even when the propositional contents themselves describe a social and interpersonal scenario, such formulations structure them into individual duties or accomplishments $(2,4)$. In other words, the indexical structure of the pattern positions the reader as an isolated agent whose role is to pursue happiness through a series of solo performances. Importantly, the effects of such indexical structures may often be harder to detect and to be critically aware of than those of explicit lexical items (see Silverstein, 2001). By singling out individuals and their actions, the patterns examined here can promote - in a fairly inconspicuous manner - the kind of individualistic and depoliticized view of happiness that has been found typical of Western neoliberal happiness discourses (see Frawley, 2015, p. 68-70).

\section{Accountability and responsibility in self-help interactions}

Finally, let us take a closer look at the discursive agents who produce the kinds of formulations examined above. The example above came from a commercial Internet portal that sells advertising space among their own editorial contents. One of the ulterior motives, then, is to make the contents appealing to the kinds of audience segments that the medium is 
targeting. Similar patterns of formulation and composition can, however, easily be found on a number of other popular sites with different kinds of funding or earning strategies. Such patterns of language-use, then, have become recognizably associated with this type of activity, which facilitates their employment across a variety of contexts. As a point of comparison, we may pick the Terve.fi ("Healthy.fi") website, a portal operated by a major Finnish media corporation. ${ }^{12}$ This site, too, offers the reader lists (" 3 tips for happiness", "10 ways to achieve happiness"), 2SG directive address (e.g., subtitles such as "Benefit from your bad mood,", "Let your thoughts run wildly through your head," "Beat your long-term depression”), siis 'so' -patterns (“According to studies, happiness strengthens the resistance [of the body], prevents getting ill, and lengthens the lifespan. So try to heal your mind."), as well as conventional pictorial imagery. On the surface, then, the websites address their readers in similar ways.

However, a major difference pertains to the institutional backgrounds of the websites. A closer look at the Askel terveyteen website reveals that it is, in fact, operated by a Spanish corporation with 300 employees and that its contents are published in 23 languages in a variety of countries. Moreover, the website includes "disclaimer" and "conditions of usage" sections making, for instance, the following statements: "the user accepts that the responsibility for the correctness, truthfulness, and flawlessness of the information transmitted via the service belongs completely to the user" and that the company is "in no way responsible for the information transmitted" and "is not responsible for any losses or damages that the user may experience because of flawed or incomplete information." This kind of regimenting metadiscourse aims to shape the social conditions and consequences of the interpretation of the object-discourse. Basically, the mediator of the discourse attempts to withdraw from all responsibility concerning the truth-value of the representations and the effectiveness of the epistemic formations, even suggesting the possibility of adverse effects. Moreover, although the site does, in a "who we are" section, list a team of trained experts with whom the site "collaborates," individual writings are usually anonymous and rarely cite any third-party references. Sometimes the formulations contain hyperlinks to other similar texts on the same website, containing more hyperlinks to similar texts on the website and so on, creating an illusion of citing references and, rhetorically, building expert ethos through the use of "external" sources. Usually, then, there is no way for the reader to verify the contents of a particular text, no substantial information on their origins, and little guarantee for their validity. In contrast, the Terve.fi portal has an editorial board and is committed to the local journalistic practices and codes of ethics. Moreover, the writers of each entry are identified, and references to, for example, medical journals are included at the end of each text.

We may conclude that, although the patterns of discursive formulation of the contents are in many ways quite similar between the two online self-help texts, in terms of responsibility and accountability, the two examples vary radically. In the latter example, the role of expert projected on the writer by the epistemic formations is not backed by the actual institutional

${ }^{12} \mathrm{https}: / /$ www.terve.fi/artikkelit/10-keinoa-tulla-onnelliseksi 
relations in which the interaction is embedded. The familiarity and recognizability of the patterns of formulation might even falsely increase their credibility. That is, as languagemediated cultural epistemologies embedded in specific social relations the two cases discussed here are quite different.

\subsection{Spontaneous online reflection on the causes of happiness}

As a contrast to the previous section, this one takes a look at models of happiness that have arisen in more informal and less mediatized interactional settings. The example is a thread from Demi.fi, an internet forum directed at teenage girls, published by the Demi magazine. ${ }^{13}$ Both the producers and the intended audiences, then, differ from the previous examples in socio-demographic terms. The thread is titled Mikä tekee sut onnelliseksi? ("What makes you happy?"). The person who had initiated the thread says in her message that it was sparked by an eponymous Finnish Hip Hop song by the artist Juju. Although the thread occurs on a commercial internet forum and was sparked by a commercial mass-media product, it is a conversation-like accumulation of individual contributions by non-professional participants. Unlike the mediatized discourses examined in the previous section, the posts in this thread represent a kind of indigenous "ethnotheoretization" of happiness. The different posts each reflect personal understandings of the causes of the experience of happiness and usually neither share a conceptual framework nor aim at describing generalizable principles or authoritative means of acquiring happiness. Together, these posts constitute a collection of accounts from various people's lives instead of a normative model or a structured set of instructions as in the previous section.

The thread begins with the initial question ("Kind of inspired by Juju, what makes you happy? :)") and a link to the song on YouTube, which are then followed by individual answers. Often the answers are quite brief, merely stating the source of happiness in one or more noun phrases.

(5) ystävät ja тии lähipiiri :)

friends and others in my close circle :)

(6) Musiikki, ystävät, perheenjäsenet ja tähtitaivas c:

Music, friends, family members and starry sky c:

(7) Kaveripoika, joka piristää aina, kun tarvistsee :'3

Male friend (lit. friend boy) who cheers one up always when one needs it :'3

Other posts are more elaborate, containing one or more clauses. In terms of indexical anchoring, most answers only involve 1 SG or 1PL deictics - describing the conditions of the writer's own happiness. Unlike in the self-help texts above, there is only one imperative in the answers addressed to the readers, or others more generally, as a 2PL group (8):

\footnotetext{
${ }^{13}$ https://www.demi.fi/keskustelu/syvalliset-mika-tekee-sut-onnelliseksi
} 
(8) Olkaa ihmiset pienestä onnellisia!

People, be happy of small things!

The temporal orientation of the answers ranges from generalizations to highly particularized descriptions (9). ${ }^{14}$ Even the generalized statements often make definite reference to particular individuals, such as friends, family members, and pets (10-12). In contrast to the previous section, the sources of happiness are usually described as something already achieved or accessible within the writer's world of experience (cf. Ahmed, 2007, p. 12). ${ }^{15}$ In fact, only one of the answers describes the source of happiness (a romantic relationship) in the conditional mood as something non-factual (13).

(9) tänään mut teki onnelliseks, että sain hapankorppua :D

'Today I was made happy by having rye crisp :D'

(10) ihan niiku siis biisis " mikä tekee sut onnelliseksi tekee mut onnelliseksi".. Mut tekee onnelliseksi se kun näkee että läheisetki on onnellisia

'just like in the song "what makes you happy makes me happy".. It makes me happy to see that loved ones are happy, too'

(11) Mun rakas ihana tyttäreni, mieheni, perheeni, ystävät (tänään mennään tyttöjen kanssa istuu iltaa

'My dear lovely daughter, husband, family, friends (going to spend the night out with the girls tonight'

(12) Mun koirat saa mut onnelliseksi joka päivä

'My dogs make me happy every day'

(13) Kai se ois se parisuhde etuineen ja ettei ärsyttäisi mikään.

'I suppose it would be a relationship with its benefits and that nothing would annoy'

Compared with the self-help texts analyzed previously, many of the answers refer to social interactions and forms of co-existence with other people, instead of individual achievements. That is, they tend to formulate happiness as an intersubjective phenomenon. Its roots are traced to social contacts with other people, and the self's happiness and others' happiness are seen as interconnected. Moreover, the items listed in the answers are presented more as everyday events, states, or occurrences, not so much as accomplishments or tasks to be fulfilled.

(14) Kolme parasta ystävääni ja niiden onnellisuus, koska ne on mulle tärkeintä täs koko maailmassa

\footnotetext{
${ }^{14}$ In this context, the answer also implicitly mediates a more general message about how happiness as a phenomenon is understood. The visible textual-interactional contrast with the generalizing statements and the sentence-initial adverbial of time ("today") underline the fact that in this view happiness arises from small mundane things and its source can vary from one day to another.

${ }^{15}$ Discussions on the temporality of happiness have emphasized the fact that many modern, neoliberalisminfluenced views of happiness tend to treat happiness as an inherently future goal, that is, as something that needs to be continuously pursued or competed for (see e.g. Ahmed 2007; cf. also section 3.1). Some views, in turn, treat happiness as an unattainable or inauthentic goal to begin with (see e.g. Duncan 2014).
} 
'My three best friends and their happiness, because they are the most important thing to me in the whole world'

(15) Hymyt ja nauru. Se että muut on hymyileviä ja onnellisia tarttuu väkisin itsellekkin. 'Smiles and laughter. That others are smiling and happy are bound to catch on oneself too.'

(16) poikaystävä, liikunta, aurinko, tuleva kesäloma, loma yleensäkki :-D oma sänky, saunominen, uimarannat, raha

'boyfriend, exercise, sun, incoming summer vacation, vacation in general :-D own bed, going to sauna, beaches, money'

(17) Liikunta, kauniit maisemat, yömyöhään juttelu kavereiden kanssa (ja kaverit ylipäätään!), lähipiirin onnellisuus, sen erään tietyn hymy.. :3 Ja hyvä ruoka hyvässä seurassa!

'Exercise, beautiful landscapes, chatting with friends until late at night (and friends in general!), happiness of loved ones, the smile of that certain person.. :3 And good food in good company!'

(18) Kaikkein eniten oon onnellinen, kun tiedän, että ollaan menossa jonnekkin reissuun 'I'm most happy when I know that we are going on a trip someplace'

In the cases examined in this section, the underlying epistemic formations by which the participants recognize happiness are not fully fleshed out and explicitly presented to others as general models, as in the previous section. Unlike in self-help discourses, the aim is not really to transmit models of happiness from one person to another. The answers are not normative instructions but, rather, aim to share personal experiences of happiness and to compare underlying views of the sources of happiness. The resulting textual structure, therefore, is often a valued-laden taxonomic listing of the constituents of a happy person's life. In other words, such textual structures regroup those aspects of a person's identity or world of experience that make it a happy one according to the particular view in question. In the examples above, such aspects involved, for instance, mental states (that nothing would annoy one), social entities (friends, loved ones; smiling people), social activity types (chatting with friends until late at night; vacations, traveling; going to sauna) as well as material possessions and environments (food, money; own bed; beaches, beautiful landscapes). Since most of the writers describe their own lives, their writings simultaneously function as idealized biographical accounts (see also Visakko 2015).

We have seen that both the contents of the models of happiness and the ways in which they are addressed to others vary significantly according to the interactional infrastructures through which they emerge. Online forums make it possible for participants to spontaneously voice their personal, experience-based (and usually non-normative) views of happiness and to comment on others' views. It should be noted, however, that the "spontaneity" of such discussions is relative and such discussion tend to serve a number of different interests. Although they do enable the users to voice their own diverse views and to perform particular kinds of online identities, they are also linked to the forum administrator's commercial activities. They attract users to the website and assemble information that can be used for a variety of purposes. In fact, similar threads have been started by the editors in order to gather 
materials for articles in preparation. ${ }^{16}$ Nevertheless, such threads give rise to a gallery of mutually differing models of happiness that others can identify with or disassociate from. That is, the link between identity and competing views of happiness becomes more visible - a point that will be developed further in the following section.

\subsection{Competing epistemologies of happiness}

In the final analysis section, we illustrate how competing cultural epistemologies model the same phenomena quite differently. The case consists of a contrast between two writers, both with a background in child education, whose ideologies clash in terms of both child-parent interactions and views of happiness. They formulate two rival models of the same social phenomena, which we analyze below. The last pair of examples also differs from the previous ones in the sense that it does not explicitly center around "happiness." A central aim in our discussion has been to approach happiness in terms of epistemological models. Here, we argue that such models can be indexically evoked by any pattern of discourse that bears a recognizable similarity with the components of a model - not solely by the lexical forms happy or happiness. As notions of happiness also circulate in discourses in which they only have an implicit or tangential role, such cases should be taken seriously. Focusing only on the most explicit and prominent cases may result in a biased view of the variety of models of happiness.

The case we discuss consists of an intertextual chain of writings: 1) The chain started with an American blog text about interactions between parents and children, titled "5 Ways to End Non-Stop Begging."17 2) This text was then republished, with minor modifications, for a larger audience on an American human interest portal YourTango, titled "5 phrases That Will INSTANTLY Make Your Kids Stop Begging". ${ }^{18}$ 3) From this portal, the text was picked up by a major Finnish online media (MTV3.fi) that published a shortened, translated version of it. ${ }^{19}$ 4) Finally, the text stirred a number of comments and reactions, including a critique by a Finnish blogger, who offered an alternative model or, indeed, a counter-model. ${ }^{20} \mathrm{We}$ may note at the outset that such intertextual chains are only made possible by modern digital infrastructures and international media practices. It is now possible for a local, non-reviewed text to make its way into a major national media on the other side of the Atlantic. It is particularly noteworthy that its contents become re-mediated into a new cultural context through a relatively direct and non-critical process of translation and abridgement. Simultaneously, the chain examined here mediates an ideological battle between two bloggers - and the cultural values they represent - on different continents.

\footnotetext{
${ }^{16}$ See https://www.demi.fi/keskustelu/syvalliset-tee-demia-mika-tekee-onnelliseksi.

17 This website is no longer publicly available.

18 https://www.yourtango.com/2015278597/5-phrases-that-will-instantly-make-your-kids-stop-begging

${ }^{19} \mathrm{https} / / /$ www.mtvuutiset.fi/artikkeli/loppu-raivareille-5-lausetta-joilla-saat-lapsen-lopettamaan-anelun/5295126. The Finnish version includes translated versions of the five interactional scenarios of the original article and frames them as a novel, newsworthy technique. Other parts of the original blog texts are omitted. The analysis in this section is based on the English language article, unless stated otherwise.

20 This website is also no longer publicly available.
} 


\section{"Happy" interactions}

The original blog text and article begin with a headnote in bold typeface saying "Take back control!," which acts as a sort of crystallizing motto for the entire text. As a directive, it also activates the kind of Adviser-Advisee relationship typical for self-help discourses (see section 3.1). Next, the writer narrates a recent, supposedly real-life story about a situation where she observed a little girl "whining and begging" for candy in a grocery store. The writer gives a turn-by-turn account of the event: After a request from the child (Mommy, can I have this?) and a refusal from the mother (No, honey), the child continued to justify the request, and the mother, after giving a reason for the refusal, ends the discussion by repeating the initial refusal: But mom, I don't have one. - We have plenty of sweets at home. - But I don't have this one. - I said no. The dialogue ends with the child crying and the mother finally giving in to the request. The writer analyzes the situation as a power struggle where "after no luck breaking her mother down" the child chose to cry as "her next strategy" and the mother was finally defeated because she "- - had just traded - - [b]asically her soul" in the negotiation.

After the introductory example, which motivates the writer's stance and choice of topic, the writer proceeds to give a five point list of advice on how to handle such interactional events with children, whom the writer describes as "mini cross-examiners" and "little whiners." According to her, each of the five points in the normative model is based on actually observed interactions:

\section{1. "Asked and answered."}

Child: "Mommy, can I have this?"

Mother: "No, honey."

Child: "But mom, I don't have one."

Mother: "Asked and answered."

Child: "You never get me anything."

Mother: "Asked and answered."

\section{2. "I'm done discussing this."}

Child: "Can Ashlyn spend the night?"

Mother: "No, she just spent the night here last week."

Child: "Please?"

Mother: "I'm not discussing this again."

Child: "But ..."

\section{3. "This conversation is over."}

Child: "Can I ride my bike?"

Mother: "No, it's raining outside."

Child: "But I'll wear my raincoat and it's only sprinkling."

Mother: "This conversation is over."

Child: "But pleeeasssee?"

Mother: "Asked and answered."

\footnotetext{
${ }^{21}$ In this example, the focal turns have been underlined by the authors.
} 


\section{4. "Don't bring it up again."}

Child: "I want these shoes."

Mother: "No, those cost too much."

Child: "But I don't like those."

Mother: "You're getting the shoes in the cart and that's final. Don't bring it up again."

Child: "I need them!"

Mother: "You brought it up again. There went your dessert for tonight.

\section{5. "The decision has been made. If you ask again there will be a consequence."}

Child: "Can I watch the iPad?"

Mother: "No, you know you're not allowed having technology at the table."

Child: "I won't get food on it."

Mother: "The decision has been made. If you ask again there will be a consequence."

Child: "But I promise!"

Mother: "I told you not to bring it up again. No iPad for the rest of the day."

In terms of social interaction, all of these five scenarios follow a similar pattern. The conversation sequence begins with a request by a child, and the mother reacts to the child's action by implementing a refusal to the request. In scenarios 2 to 5, the mother's answer also gives a reason for the refusal in the same turn (e.g. she just spent the night here last week; it's raining outside), which can be expected in dispreferred actions in everyday conversation (see e.g. Pomeranz and Heritage, 2013, p. 215). In the child's second turn, all of the scenarios have the child challenging the mother's decision, either by giving competing reasons for the original request $(1,3-5)$ or by adding a conventional signal of politeness to it (2).

The second turn by the mother is where the proposed techniques come into play. These techniques can be further divided into two approaches. Solutions 1 to 3 are essentially variations of the same technique, stating an explicit one-sided conclusion to the interaction: Asked and answered (1), I'm not discussing this again (2), or This conversation is over (3). In all of these scenarios, the child is presented as protesting the mother's decision, either by producing a negative generalized assessment of the mother's actions (1), by implementing a but-prefaced challenge to her turn (2), or by uttering an emphatically prolonged particle please (3). The interaction is presented as ending with the mother simply repeating her previous turn (1), withdrawing from conversation (2) or using a near-synonymical paraphrase of her previous expression (3). Techniques 4 and 5 add a threat and a punishment to the model. In scenario 4, the mother's second turn is a negative directive (Don't bring it up again.), and, after the child persists on the topic, the mother declares a punishment (There went your dessert for tonight.). In scenario 5, the mother starts her second turn by stating that the decision has been made and continues with a non-specific threat: if you ask again there will be a consequence. After the child brings the request up again, the threat becomes actualized as a specific punishment (no iPad for the rest of the day). ${ }^{22}$

\footnotetext{
${ }^{22}$ According to the instructions in the article, verbal action should also be reinforced non-verbally with "devil eyes" and by "simply walking away." The writer anticipates that the conversations are initially going to end in crying and tantrums, but after this "testing stage" the parent will "earn" the "child's respect".
} 
Basically, then, the proposed model has two dimensions: withdrawing from interaction through mechanical repetition (1 to 3 ) and enforcing compliance on the other participant by threatening with adverse consequences (4 to 5). This allows the parent to avoid reasoning, renegotiating, or engaging with challenges and to maintain an explicit power asymmetry, which is reflected in the metaphorical expressions used in the article to describe the participant roles and the nature of the interaction: "take charge," "take back control," "won the battle." Finally, the writer demonstrates the success of the model with a conversation she claims to have had with her 4-year old daughter while writing the article. The writer specifies explicitly that the following conversation exemplifies the "happy" and "blissful" effects the proposed model produces.

Charlotte: "Can I have a cookie?"

Me: "Yes, you may have one."

Charlotte: "Can I have three?"

Me: "This conversation is over."

Charlotte: "OK, I'll just break it in half so I can have two."

According to the writer, even "some passive-aggressiveness" from the child's part poses no problem, as the parent "still won the battle." Happiness of the self, then, becomes implicated in power relations and others' emotions.

Thus, the writing mediates an ideologically biased epistemic formation that maps the notion of happiness on the discursive practices of everyday conversation, such as turn-taking, preference hierarchies, and action sequences. It theorizes links between what one should observe in a child's behavior and how one should respond to the child's behavior from the standpoint of the parent, the dominant participant. An interpersonal encounter between a parent and a child can be classified as "happy" if it satisfies the criteria set by the dominant participant and coheres with the cultural values (e.g., obedience, discipline) that the latter is committed to. It is particularly noteworthy, in light of the previous examples and the discussion in the introductory section, that this view seems to background affective processes and links the term "happy" primarily to overt interpersonal interactions.

In this first example, the only direct reference to happiness is the use of the adjective "happy" [interactions], which could also here be construed as something like 'successful' or 'smooth'. Combined with "blissful," it nevertheless seems to activate the more prototypical, happinessattributing meaning of the word, although in a somewhat ironic tone. In the Finnish-language translation, in fact, this part had been omitted entirely (as perhaps stylistically unsuitable). However, aside from the adjective, we argue that there are numerous other discursive patterns that forge type-level indexical links with the kinds of models of happiness often seen in happiness-centric self-help. For instance, the text deals with the causes of desired (versus non-desired) mental states and ideal (versus non-ideal) social statuses, and it tends to portray them as valued, ultimate identity goals. More generally, the text incorporates many 
recognizable patterns of self-help discourses, such as offering points of observation and intervention. Importantly, in the Finnish-language blog response, which we will examine next, the effects of the original model are discussed in terms of "well-being" (hyvinvointi). That is, the response shows that the original becomes interpreted as a model aiming, but failing, to generate well-being.

\section{Ideological conflict}

In any society, different epistemologies tend to conflict with one another, and sometimes such conflicts become explicitly negotiated in social interaction. The blog text examined above and its different remediated versions sparked a number of heated discussions. Once the writing was picked up by a major Finnish news media, a Finnish blog writer targeted heavy criticism at it, claiming that such instructions are "at worst quite a load of psychological violence" (pahimmillaan aikamoista henkistä väkivaltaa) and that the presented model "is useful only if the grown-up is concerned with his or her own well-being" (on hyödyllistä vain silloin, jos aikuista kiinnostaa ainoastaan aikuisen oma hyvinvointi). She also presents an alternative model that we will examine below. We may note that the model examined above was presented as a general one, non-selective of its audience. Only the subsequent critiques and counter-models it gave rise to make its value-laden nature more explicit. Such interdiscursive dialectics, then, highlight the fact that each model is specifically linked to particular cultural values and social identities.

The Finnish blogger presents an alternative model based on listening, dialogue, and displays of empathy. The five competing techniques that she suggests to parents in a similar situation are the following:

1. "You seem to be awfully angered." (Sua taitaa suututtaa ihan kamalasti.)

2. "I notice that it is very important for you." (Mä huomaan, että se on sulle tosi tärkeää.)

3. "At the same time..." (Samaan aikaan ...)

4. "What could we come up with?" (Mitäs me keksittäis?)

5. "I love you, and it is important to me that you feel well." (Rakastan sinua, ja mulle on tärkeää, että sulla on hyvä olla.)

In this model, the techniques are supposed to be used in succession. Each one is accompanied by a brief explanation of how, specifically, it should be used and why. The first expression acknowledges the other's negative emotions. ${ }^{23}$ Acknowledging the other's emotional state is

\footnotetext{
${ }^{23}$ The Finnish-language original features the emotional causative verb suututtaa ('be angered') that foregrounds the emotional process the child is undergoing. Causative verbs prototypically thematize the patient of the emotion (i.e., the grammatical object). The cause of the emotion (i.e., the grammatical subject) is an optional constituent in such sentence-frames. The explanation also cites other similar verbs, such as surettaa ('be saddened'), turhauttaa ('be frustrated'), and pelottaa ('be frightened') as alternatives, to correspond to the child's emotional state.
} 
central also in the second expression - a performative utterance with which the parent states that they are aware of the child's emotional attachment to the object of their desire ("I notice that it is very important for you"). According to the writer, the aim is to show to the child that the parent respects "their needs, wants, and thoughts." The third expression entails a shift in perspective by giving reasons for the refusal of the child's wishes. According to the writer, "at the same time" communicates that both the child and the parent have equally important needs and wishes: "I [ = parent] don't put aside my need, but I also don't put aside the child's need just because I am an adult and I have the power and the right of way." The fourth expression is a request of information that uses the inclusive first person plural, referring to both the parent and the child together. The speaker invites the addressee to join in the search for a solution that reconciles the interests of both participants. The fifth item expresses affiliation with and positive emotions towards the addressee. According to the writer, its purpose is to bring the parent back to the thought that "the most important thing is a loving and close relationship between me and my child."

In both examples, everyday interactional practices become the objects of epistemic formations. There is, however, an explicit ideological contrast between the two competing formations. Both target the same or similar observable behaviors but theorize them differently and suggest strictly divergent practical interventions. That is, they disseminate conflicting models of the relationship between happiness and parent-child interactions. Moreover, the ideological contrasts become explicitly linked to specific social identities both within the texts themselves and in their comment feeds. In the readers' comments, both views received explicit, public support. The readers also further justified either their support for or objections to one or the other model with arguments and counter-arguments relying on specific cultural values. For instance, the original model was frequently associated, by both supporters and opponents, with old-fashioned, authoritative parenting with ideals of discipline and hierarchy. We see, then, that views of happiness are inherently linked to politics of identity and presuppose the kinds of cultural norms and values that individuals in particular communities are committed to. Ideas about happiness and ideas about social conduct more generally become intertwined.

Finally, we may note that such epistemic formations embody specific understandings of the very nature of language and culture. The original blog text, in particular, implies that interactional problems can be solved simply by playing a pre-definable, routine-like set of roles and replicating the same set of behaviors from one context to another. In fact, such mechanical, decontextualized views seem to be common to many genres of happiness-related self-help. They often show little sense of social and cultural variation according to types of activities or identities. That is, they tend to reduce the participants of social interaction to one-dimensional characters - instead of, for example, focusing on how to develop more flexible selves and solutions adjusted to specific types of encounters with specific types of persons (cf. Frawley, 2015, p. 69).

\section{The social and cultural life of happiness}


We have argued that the object called "happiness" comes to life through a complex interplay of social interactions and discursive practices. Happiness is relative to the cultural epistemologies in light of which human experience becomes evaluated. Our focus has not been on the contents of any specific understanding of happiness but, rather, on the emergence, variation, and circulation of such understandings in society through the internetmediated Finnish-language discursive space. We have shown that such patterns of social interaction constitute a metaculture of happiness, as they selectively disseminate particular kinds of models accelerating their movement in society at the expense of competing variants. It has been noted by many scholars (e.g. Duncan, 2007; Frawley, 2015, p. 65) that the modern focus on happiness thrives in the vacuum left by religious and political ideologies - or previous popular psychological notions (e.g., "self-esteem"). In particular, it has been noted that neoliberal discursive forces boost individualistic notions of happiness, which may consequently have a depoliticizing effect, diverting critical attention from social issues (e.g. Mentinis, 2013). Our examples have echoed such tendencies (3.1), but they have also shown that once smaller-scale "indigenous" views of happiness come into play, we find both more variety in views of happiness, including non-individual-centric ones (see 3.2), and identitypolitical struggles around the notion of happiness (see 3.3).

We have approached happiness as a discursive construct. In particular, we have aimed to clarify how the formulation of a model of happiness affects the object of the model. For instance, we found that the indexical organization of models of happiness may itself contribute to an individualistic understanding of happiness, regardless of the actual propositional content (see 3.1). The analyses also showed significant differences in happiness-related self-help instructions and biographic accounts of happiness in terms of linguistic formulation, interactional organization as well as social accountability and responsibility. Moreover, we have shown that important - and often some of the more concrete - aspects of views of happiness may become disseminated alongside discussions on other topics, such as parenting (see 3.3). Research on views of happiness, then, should also include discourses in which happiness is not a focal topic.

Theoretically, we have approached models of happiness as cultural epistemology that manifests itself through epistemic formations. Through the intermediary of linguistic representations, epistemic formations direct our attention to specific observable objects of experience and guide our practical interventions on those objects. Our aim has been to show in detail the everyday discursive and ideological dynamics of culturally contingent understandings of happiness (cf. e.g. Jugureanu \& Hughes, 2010; Duncan, 2014). We have examined how epistemic formations become linked to competing social identities and to the value hierarchies that those identities are based on: how we theorize happiness, as a function of who we are, specifies where we can recognize happiness and how we aim to contribute to its realization. Commercial media, in particular, seem to favor one-fits-all and fix-it-all formulas. However, the concrete implementation of such models in actual interactions with one's social and physical environments is often left quite vague in terms of empirical 
observations and practical interventions. Also, they tend to leave little room for flexibility, context-sensitivity, and cultural variation of interactional practices.

Simultaneously, we have illuminated a number of different ontological levels at which language contributes to the construction of happiness. Firstly, language serves as an instrument of communication and role-inhabitance. It shapes social relations between people, such as children and parents in everyday interactions, and has, therefore, an experiencegenerating function. Secondly, language functions as an instrument of inferential and narrative organization. It can be used to re-interpret and re-structure previous experiences, as in section 3.3, where the writer recounted a problematic parent-child interaction and generalized her perception of it into a normative model. Thirdly, then, language shapes the underlying assumptions that social interactions and personal experiences rely on in the first place. When linguistic representations become part of epistemic formations and when those epistemic formations become replicated in communities and internalized by individuals, they start guiding the empirical observations and practical interventions by which people aim at cultural goals, such as "happiness." Language, thus, serves as an instrument of reflexive selfshaping and metacultural world-making. Importantly, language is sometimes itself implicated as an object in such linguistically articulated models of happiness. That is, models of happiness may include specific ideas about the kinds of language-use that contribute to happiness (see 3.3).

Moreover, we have aimed to illustrate that talking about happiness and experiencing happiness are quite different things. Insofar as a model of happiness targets relatively private processes, such as emotions or self-conceptions, talk about happiness may occur independently of those objects of experience. Epistemic formations may be incoherent, faulty, or insincere. What we say about our own or others' happiness might not correspond with our actual observations. Similarly, the beliefs we have about our own or others' happiness may lead to interventions that do not actually lead to the kinds of observable effects that we desire. In a society where happiness and success are important indices of social status and prestige or forms of symbolic capital - that is, in neoliberal "happycracies" (see Cabanas and Illouz 2019) - one may feel considerable pressure to portray an air of happiness even if one does not actually experience that kind of happiness. Importantly, then, talking about "happiness" has its own logic, which only partially coincides with actually experiencing the object 'happiness' that the term denotes within some epistemology. Therefore, we regard a critical awareness of the discursive nature and the interactional dynamics of any model of happiness as crucial to a full understanding of the phenomenon.

\section{Acknowledgement}

The authors would like to thank the anonymous reviewer for an insightful and constructive review and for valuable suggestions that greatly improved the article. We would also like to thank Laura Visapää, Ilona Herlin, Jennifer De Paola, Barbara Fox, and Cecilia Ford, whose input, either as members of the Happiness Project (2014-2016) or as co-panelists at the 
International Symposium for Contemplative Studies (2016), helped shape the direction of this article. In addition, Tomi Visakko would like to thank the Kone Foundation, whose grant enabled part of this work. Eero Voutilainen would like to thank the Finnish Centre of Excellence in Research on Intersubjectivity in Interaction for supporting this research.

\section{Declaration of interests}

None.

\section{Funding}

Early stages of this work were partially supported by the Kone Foundation and the Finnish Centre of Excellence in Research on Intersubjectivity in Interaction.

\section{References}

Agha, A., 2007. Language and social relations. Cambridge University Press, Cambridge.

Agha, A., 2011. Meet mediatization. Language \& Communication 31 (3), 163-170.

Agha, A., 2015. Enregisterment and Communication in Social History. In: Agha, A., Frog (Eds.), Registers of Communication. Finnish Literature Society, Helsinki.

Ahmed, S., 2007. Happiness Turn. New Formations 63, 7-14.

Aristotle [2009]. The Nicomachean Ethics. Edited by Lesley Brown. Translated by David Ross. Oxford University Press, Oxford.

Bateson, G., 1972. Steps to an Ecology of Mind. The University of Chicago Press, Chicago.

Bhatia, V., 2004. Worlds of written discourse. Continuum, London.

Brandom, R., 2000. Articulating Reasons. An Introduction to Inferentialism. Harvard University Press, Cambridge.

Bruckner, P. 2010. Perpetual Euphoria: On the Duty to Be Happy. Princeton University Press, Princeton.

Cabanas, E., Illouz, E., 2019. Manufacturing Happy Citizens. How the Science and Industry of Happiness Control Our Lives. Polity Press, Cambridge.

Chiao, J. (Ed.), 2009. Cultural Neuroscience: Cultural Influences on Brain Function. Progress in Brain Research 178. Elsevier, New York. 
Chilton, P. 2004. Analysing Political Discourse. Theory and Practice. Routledge, London.

Douglas, M., 1972. Self-Evidence. Proceedings of the Royal Anthropological Institute of Great Britain and Ireland 1972, 27-43.

Duncan, G. 2007. After happiness. Journal of Political Ideologies 12(1), 85-108.

Duncan, G. 2014. Politics, Paradoxes and Pragmatics of Happiness. Culture, Theory, and Critique 55(1), 79-95.

Frawley, A., 2015. Happiness Research: A Review of Critiques. Sociology Compass 9 (1), $62-77$.

Gal, S., 1989. Language and political economy. Annual Review of Anthropology 18: 345367.

Goddard, C., Ye, Z., 2014. Exploring "happiness" and "pain" across languages and cultures. International Journal of Language and Culture 1 (2), 131-148.

Griffin, J. M., 1998. Happiness. In: Craig, E. (Ed.), Routledge Encyclopedia of Philosophy. Routledge, London.

Hanson, R., 2013. Hardwiring happiness: The practical science of reshaping your brain - and your life. Rider, London.

Holtmaat, A., Svoboda, K., 2009. Experience-dependent structural synaptic plasticity in the mammalian brain. Nature Reviews Neuroscience 10 (9), 647-658.

Irvine, J., 1989. When talk isn't cheap: Language and political economy. American Ethnologist 16 (2), 248-267.

Jugureanu, A., Hughes, J. 2010. Lay theories and the cultural contingency of happiness. ESA Research Network Sociology of Culture Midterm Conference: Culture and the Making of Worlds, October 2010.

Jugureanu, A., Hughes, J., Hughes, K. 2014. Towards a Developmental Understanding of Happiness. Sociological Research Online 19 (2).

Kockelman, P., 2006. Representations of the world: Memories, perceptions, beliefs, intentions, and plans. Semiotica 162 (1), 73-125.

Kockelman, P., 2013. Agent, person, subject, self. A theory of ontology, interaction, and infrastructure. Oxford University Press, New York. 
Kroskrity, P., 2004. Language ideology. In: Duranti, A. (Ed.), Companion to linguistic anthropology. Blackwell, Oxford, pp. 496-517.

Kövecses, Z., 2008. The conceptual structure of happiness. In Salmela, M., Pessi, A., Tissari, H. (Eds.), Happiness: Cognition, Experience, Language. Studies across Disciplines in the Humanities and Social Sciences 3. Helsinki Collegium for Advanced Studies, Helsinki, pp. 131-143.

Lakoff, G., 1987. Women, Fire, and Dangerous Things: What Categories Reveal About the Mind. University of Chicago Press, Chicago.

Legrenzi, P., Umilta, C. 2011. Neuromania: On the Limits of Brain Science. Oxford University Press, Oxford.

Levinson, S., 1992 [1979]. Activity types and language. In: Drew, P., Heritage, J. (Eds.), Talk at work: Interaction in institutional settings. Cambridge University Press, Cambridge.

Levisen, C., 2014. The story of "Danish Happiness": Global discourse and local semantics. International Journal of Language and Culture 1 (2), 174-193.

Lutz, A., Greischar, L., Rawlings, N., Ricard, M., Davidson, R., 2004. Long-term meditators self-induce high-amplitude gamma synchrony during mental practice. PNAS 101 (46).

Mead, G. H., 1934. Mind, Self, \& Society. From the standpoint of a Social Behaviorist. The University of Chicago Press, Chicago.

Mentinis, M. 2013. The Entrepreneurial Ethic and the Spirit of Psychotherapy:

Depoliticisation, Atomisation and Social Selection in the Therapeutic Culture of the 'crisis'. European Journal of Psychotherapy \& Counselling 15 (4), 361-374.

Parmentier, R., 1994. Signs in society. Studies in semiotic anthropology. Indiana University Press, Bloomington.

Pomeranz, A., Heritage, J., 2013. Preference. In: Sidnell, J., Stivers, T. (Eds.), The Handbook of Conversation Analysis. Wiley-Blackwell, Chichester.

Ricard, M., 2006. Happiness. A guide to developing life's most important skill. Little, Brown and Company, New York.

Sacks, H., Schegloff, E., Jefferson, G., 1974. A simplest systematics for the organization of turn-taking for conversation. Language 50 (4), 696-735. 
Salmela, M., Pessi, A., Tissari, H., 2008. A Happy Introduction. In Salmela, M., Pessi, A., Tissari, H. (Eds.), Happiness: Cognition, Experience, Language. Studies across Disciplines in the Humanities and Social Sciences 3. Helsinki Collegium for Advanced Studies, Helsinki, pp. 4-11.

Schegloff , E., 2007. Sequence organization in interaction: A primer in conversation analysis. Cambridge University Press, Cambridge.

Schieffelin, B., Ochs E. (Eds.), 1986. Language Socialization Across Cultures. Cambridge University Press, Cambridge.

Schwartz, J., 2003. The Mind \& The Brain. Neuroplasticity and the Power of Mental Force. HarperCollins Publishers, New York.

Schutz, A., 1967. The Phenomenology of the Social World. Northwestern University Press, Evanston.

Seligman, M., 2002. Authentic Happiness: Using the New Positive Psychology to Realize Your Potential for Lasting Fulfillment. Simon \& Schuster, New York.

Silverstein, M., 1979. Language structure and linguistic ideology. In: The Elements: A parasession on linguistic units and levels. Chicago Linguistic Society, Chicago.

Silverstein, M., 2001. The limits of awareness. In: Duranti, A. (Ed.), Linguistic Anthropology: A Reader. Blackwell, Malden.

Silverstein, M., 2003. Indexical order and the dialectics of sociolinguistic life. Language \& Communication 23 (3), 193-229.

Silverstein, M., 2004. "Cultural” Concepts and the Language-Culture Nexus. Current Anthropology 45 (5), 621-652.

Sorjonen, M., Raevaara, L., Couper-Kuhlen, E., 2017. Imperative Turns at Talk: An Introduction. In: Sorjonen, M., Raevaara, L., Couper-Kuhlen, E. (Eds.), Imperative turns at talk. The design of directives in action. Benjamins, Amsterdam, pp. 1-24.

Tallis, R. 2011. Aping Mankind: Neuromania, Darwinitis and the Misrepresentation of Humanity. Acumen, London.

Tambiah, S., 1985. Culture, Thought, and Social Action. An Anthropological Perspective. Harvard University Press, Cambridge.

Thompson, E., Varela, F., 2001. Radical embodiment: neural dynamics and consciousness. Trends in Cognitive Sciences 5 (10), 418-425. 
Urban, G., 2001, Metaculture. How culture moves through the world. University of Minnesota Press, Minneapolis.

Visakko, Tomi 2015: Self-Promotion as Semiotic Behavior. The Mediation of Personhood in light of Finnish Online Dating Advertisements. (Doctoral dissertation.) University of Helsinki, Helsinki. URL: http://urn.fi/URN:ISBN:978-951-51-1399-3

WDH 2019 = World Database of Happiness. Archive of research findings on subjective enjoyment of life. URL: https://worlddatabaseofhappiness.eur.nl/

Wilce, J., 2009. Language and Emotion. Cambridge University Press, Cambridge.

Wierzbicka, A., 2004. 'Happiness' in a cross-linguistic and cross-cultural perspective. Daedalus 133, 34-43.

Wierzbicka, A., 2011. What's wrong with "happiness studies". The cultural semantics of happiness, bonheur, Glück and Sčast'e'. In: Boguslavskij, I., Iomdin, L., Krysin, P. (Eds.), Slovo i Jazyk. Jazyki slavjanskoj kultury, pp. 155-171.

Woolard, K., Schieffelin, B., 1994. Language ideology. Annual Review of Anthropology 23, 55-82. 